\title{
Measuring Aversion to Health Risks
}

\author{
*Joseph G. Eisenhauer ${ }^{1}$, Kristine E. Principe ${ }^{2}$ \\ ${ }^{1}$ University of Detroit Mercy, Michigan, USA \\ ${ }^{2}$ Niagara University, USA \\ *joseph.eisenhauer@udmercy.edu
}

\begin{abstract}
Researchers have commonly used financial gambles to assess risk preferences, though attitudes regarding monetary gambles may differ from those concerning health risks. Moreover, the conventional measure of risk preference-the Pratt-Arrow coefficient of relative risk aversion-is a point-elasticity suitable only for trivial risks, whereas the risks pertaining to medical treatment-often involving life-ordeath decisions-are quite substantial. Our objective is to examine attitudes toward health risks and the variables that influence those attitudes. In addition to the conventional metric, we employ an alternative measure of risk aversion designed for large-scale risks; the latter is calculated as an arc-elasticity of marginal utility. Both measures are applied to responses from a health preference survey, which incorporates a standard gamble over longevity. Measured risk aversion is then related to health and demographic variables using multiple linear regressions. Our research suggests that tolerance of health risks may be influenced by an endowment effect reflecting the asymmetry of medical information between patients and providers. We also find that the arc-elasticity measure captures more of the significant differences and has a stronger correlation to demographic and socio-economic variables than does the more traditional point-elasticity measure, indicating that the conventional measures of risk aversion are indeed ill suited to large-scale risks such as those involving health. In addition, our results suggest that health-related risk preferences may differ from financial risk attitudes. Although our sample is relatively small and largely homogeneous, these results collectively provide a basis for replication and a justification for additional study on the measurement of risk aversion with regard to health.
\end{abstract}

Keywords: Health care; standard gamble; risk aversion; arc-elasticity; longevity

\section{Introduction}

Medical care is inherently risky, and patients - as well as physicians, nurses, and other care providers-tend to be risk averse. Numerous studies have examined the relationship between risk preferences and demographic variables, including health and health-related choices. ${ }^{1}$ However, researchers have commonly used financial gambles to assess risk preferences, though attitudes regarding monetary risks may differ from attitudes regarding health risks. As Anderson and Mellor (2008) note, "there is not unanimous support for linking measures of financial risk tolerance to measures of risk tolerance in other settings, such as health." Thus, the present paper measures risk preferences using survey questions in a health-related context. Moreover, the conventional measure of aversion to risk-the Pratt-Arrow coefficient of relative risk aversion-is a local measure suitable only for trivial risks, whereas the risks pertaining to medical treatment-often involving life-or-death decisions-are anything but trivial. In addition to the conventional measure, therefore, we employ an alternative, global measure of risk aversion designed for large-scale risks. Both metrics are applied to a standard gamble involving longevity and then correlated with demographic and health factors using multiple linear regression. We find that health-related risk preferences differ from financial risk preferences among smokers and those in poor health, and that our alternative measure of risk aversion captures more of the significant differences involving socio-economic variables than does the traditional measure. In addition, by framing the standard gamble in two different ways, we find evidence of health-related endowment effects. Section 2 gives an overview of the risk aversion literature and describes the standard gamble methodology. Section 3 distinguishes between the two-risk aversions metrics used in

\footnotetext{
${ }^{1}$ See, for example, Hammitt, et al. (2009), Barsky et al. (1997), Eisenhauer and Ventura (2003), and Anderson and Mellor (2008).
} 
this study. Section 4 describes the survey data and empirical results, comparing them to prior research. Section 5 provides a short conclusion.

\section{Literature Review}

A basic tenet of consumer theory is that an individual maximizes utility-a preference function defined over goods, money, or other outcome variables. Further, it is widely understood that if a univariate utility function is concave (linear, convex), then the individual to whom it belongs exhibits aversion (neutrality, love) toward risk, where risk is defined by the variance in the outcome variable. Thus, for nearly half a century following the seminal work of Pratt (1964) and Arrow (1965), economists have measured an agent's aversion to risk by calculating the curvature of the utility function; as explained below, this is customarily done by evaluating the first and second derivatives of the function. The contributions in this field are so numerous that several textbooks and literature reviews have now appeared (Eeckhoudt et al. 2005, Meyer and Meyer, 2005, and Heinzel, 2009). The vast majority of this literature has measured risk aversion in financial contexts such as investments or gambling, in which the outcome variable is pecuniary. Among the most prevalent findings are that financial risk aversion is higher among the elderly than others are, higher among women than men are, and decreasing in education. Health economists, however, have long recognized that risk is not a uniquely monetary phenomenon; risks to health can occur both naturally and because of medical treatment. Understanding patients' attitudes toward such risk is now considered essential to providing quality health care; as van der Pol and Ruggeri (2008) note, "the optimal treatment from a patient's perspective will depend amongst other things on their risk attitude." Because attitudes to health risks tend to differ from attitudes toward monetary risks (Prosser and Wittenberg, 2007), it is necessary to examine patient preferences in a health-specific context.

The Standard Gamble: To assess patient attitudes toward health risks, the standard gamble has been widely used in medical research. Indeed, it is often viewed as the "gold standard" for evaluating preferences concerning health states (Ben-Zion and Gafni, 1983; Puhan, et al. 2007). Furthermore, as Torrence et al. (2002) point out, "The standard gamble is the only measurement method that captures the respondent's risk attitude and thus provides a measure that is appropriate for decisions with uncertainty." Several versions of the standard gamble have been utilized in the health services research literature. In one, a subject is told that a risky treatment will result in either a good outcome $(G)$ with probability $p$ or a bad outcome $(B)$ with probability $1-p$, and is then asked what certain outcome $(C)$ would generate as much satisfaction as facing the gamble, where outcomes are typically measured in years of healthy living. Examples of this approach include the studies by Verhoef, et al. (1994), Nakata, et al. (2000), Prosser and Wittenberg (2007), and van der Pol and Ruggeri (2008). ${ }^{2}$ In another version, the subject confronts a choice between a certain outcome and a risky outcome, and is asked what probability $(p)$ of a good outcome would make him or her indifferent between the risky outcome and the certain outcome (see for example, Gyrd-Hansen (2002) and Oliver and Cookson, (2010)). In either case, the expected utility equation is the same: for a utility function $U$ defined over the lifetime $X$, the utility from the certainty equivalent is equal to the expected utility of the gamble. Thus,

$$
U(C)=p U(G)+(1-p) U(B) .
$$

For an initial value (i.e., current age) of $X_{0}$, the good outcome is $G=X_{0}+\gamma$, the bad outcome is $B=X_{0}+\beta$, and the certainty equivalent is $C=X_{0}+\mu-\pi$, where the mean of the gamble is $\mu=p \gamma+(1-p) \beta$, and its variance is $\sigma^{2}=(\gamma-\beta)^{2} p(1-p)$. The risk premium $\pi$ is the difference between the expected lifetime, $E(X)=X_{0}+\mu$ and its certainty equivalent. For any given risk, a lower certainty equivalent (or

\footnotetext{
${ }^{2}$ Two variants of this approach have been used. In one, the respondent is directly asked to state the certainty equivalent of a risk; in the other, pairs of lotteries are ranked until the respondent expresses indifference, and the certainty equivalent is inferred from the choice. For a comparison, see Law, et al. (1998).
} 
larger risk premium) indicates greater aversion to the risk. Indeed, $B \leq C<E(X)$ implies risk aversion, $C=$ $E(X)$ implies risk neutrality, and $E(X)<C \leq G$ implies a love of risk. ${ }^{3}$

Point and Arc Elasticity Measures of Risk Aversion: In order to draw comparisons across individuals and/or across risks, the results of the standard gamble are typically converted into a numeric measure of risk aversion. Following Pratt (1964) and Arrow (1965), one such metric is the coefficient of absolute risk aversion, defined as the negative ratio of the second derivative of utility to the first derivative; that is, $a(X)=-\mathbb{U}^{\mathrm{m}}(X) / U^{y}(X)$; see for example Johannson (1995). Because utility is not directly observable, it is necessary to either impose an assumption regarding the functional form of utility, or adopt Pratt's (1964) approximation, $a(X) \approx 2 \pi / \sigma^{2}$, to make this measure operational. ${ }^{4}$ However, the coefficient of absolute risk aversion is not elasticity, but rather, is sensitive to the units in which the outcome is measured (for example, whether wealth is measured in dollars or euros, or whether time is measured in years or months). To convert $a(X)$ into an index number, Pratt (1964) and Arrow (1965) multiply $a(X)$ by $X$ to define the coefficient of relative risk aversion, $r(X)=X a(X)$, which represents the point elasticity of marginal utility with respect to $X$. Pratt's approximation then gives $r(X) \approx 2 X \pi / \sigma^{2}$. Unfortunately, both the exact and approximate coefficients are based on differential calculus, and are therefore applicable exclusively to infinitesimal changes in the argument of the utility function; that is, they are only suitable for use with trivial risks (Eisenhauer, 2006, 2008)..$^{5}$ Thus, Pratt (1964) described them as "risk aversion in the small". For large risks, the Pratt-Arrow coefficient often yields perverse rankings of preferences (Eisenhauer, 2010a), and frequently fails to capture statistically significant differences between population subgroups (Eisenhauer and Ventura, 2011). ${ }^{6}$

To address these problems, an arc elasticity measure of risk aversion has been developed for use with large, discrete changes (Eisenhauer, 2006); the new metric is especially suited to standard gambles involving two risky states (Eisenhauer, 2010b). From (1), define the following discrete utility changes, or discrete marginal utilities:

$$
\begin{aligned}
& M U_{1}=[U(C)-U(B)] /[C-B] \\
& M U_{2}=[U(G)-U(C)] /[G-C] \\
& M U_{A}=[D(G)-U(B)] /[G-B]
\end{aligned}
$$

As depicted in Figure 1, $M U_{1}, M U_{2}$, and $M U_{A}$ represent the slopes of chords along a utility function from $B$ to $C$, from $C$ to $G$, and from $B$ to $G$, respectively. ${ }^{7}$ If equations (2) through (4) were calculated in the limit as the

\footnotetext{
${ }^{3}$ Under the assumption that longevity is good and more is therefore preferred to less, $C<B$ or $C>G$ indicates irrationality.

${ }^{4}$ The Pratt-Arrow coefficient is based on small changes in a continuous variable, originally taken to be wealth. For riskless wealth $X_{0}$ and risky wealth $\mathcal{Z}$ with a mean of $\mu=E(\mathcal{Z})$, the expected utility equation is $U\left(X_{0}+\mu-\pi\right)=E U\left(X_{0}+\mathcal{Z}\right)$. Taking a Taylor series approximation, Pratt (1964) derived $U\left(X_{0}+\mu\right)-\pi U^{0}\left(X_{0}+\mu\right) \approx U\left(X_{0}+\mu\right)+E(Z-\mu) U^{0}\left(X_{0}+\mu\right)+0.5 \sigma^{2} U^{m}\left(X_{0}+\mu\right)$, which gives $a(X)=-\mathbb{U}^{\mathrm{m}}(X) / U^{\mathrm{V}}(X) \otimes 2 \pi / \sigma^{2}$ where $X=X_{0}+\mu$. Thus, $a(X)$ measures absolute risk aversion at a single point: the expected value of final wealth.

${ }^{5}$ By definition, a derivative is the change in a function (e.g., utility) as the change in its argument approaches zero in the limit; thus $\mathbb{V}^{g}(X) \equiv \lim _{\boldsymbol{h} \rightarrow 0}[U(X+h)-U(x)] / h$, so that risk preference metrics based on derivatives are appropriate only for infinitesimal risks.

${ }^{6}$ Using the Pratt-Arrow coefficient of absolute risk aversion in a health context, Nakata et al. (2000) found no significant differences in risk aversion between anesthesiologists and surgeons, regardless of whether they viewed themselves as patients or health care providers, and no significant difference between men and women.

${ }^{7}$ The concavity of the utility function in Figure 1 depicts risk aversion, but this is merely one possibility. A risk lover's utility function would exhibit convexity between $B$ and $G$.
} 
denominators of their right-hand sides went to zero, each would denote a first derivative of utility, or a marginal utility "in the small".

\section{Figure 1: Utility Function for a Risk Averse Individual}

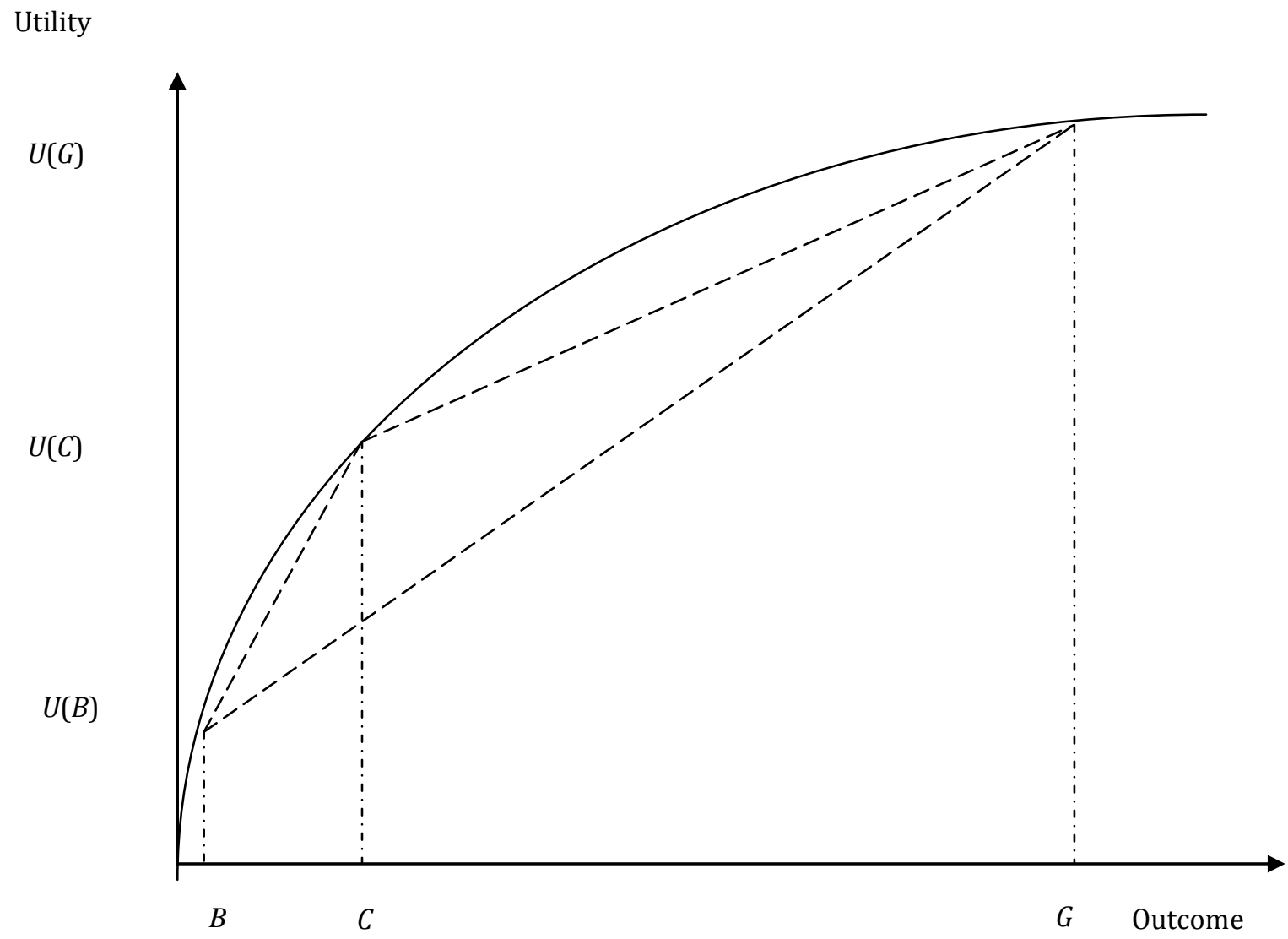

Notice that $M U_{A}$ is a weighted average of $M U_{1}$ and $M U_{2}$ :

$$
(G-B) M U_{A}=(G-C) M U_{2}+(C-B) M U_{1}
$$

In addition, (1) can be rewritten as

$$
(C-B) M U_{1}=p(G-B) M U_{A} .
$$

Substituting (6) into (5) generates

$$
(1-p)(G-B) M U_{A}=(G-C) M U_{2} .
$$

To construct an arc elasticity measure of relative risk aversion, we divide the difference in discrete marginal utilities, $M U_{1}-M U_{2}$, by their average, $M U_{A}$. From (6) and (7), this gives

$$
R=\frac{W W_{1}-W W_{2}}{W W_{A}}=\frac{P(Q-B)}{C-B}-\frac{(1-p)(G-B)}{G-C}
$$


Notice that the units of measurement cancel in (8), so that $R$ is a pure index number. ${ }^{8}$ To simplify the result, the certainty equivalent can be transformed into $c=(C-B) /(G-B)$, where $0 \leq c \leq 1$ for all $B \leq C \leq G$. The arc elasticity measure of risk aversion can then be written as

$$
R=(p-c) /\left(c-c^{2}\right) .
$$

The measure of risk aversion given in (9) is quite general in that it does not assume any particular shape or functional form of utility. For an individual who exhibits aversion to a given risk, $R>0$; for a love of risk, $R<0$, and $R=0$ for risk neutrality. ${ }^{9}$ As an example, consider a health risk in which the good outcome is an additional 25 years of life, which occurs with probability 0.5 , and the bad outcome is only one additional year with probability 0.5 ; the mean is 13 years, the variance is 144 , and the standard deviation is 12 years. Suppose that the individual is currently 24 years old, so the expected lifetime is 37 years. Suppose further that the certainty equivalent is 36 years, as it would be if the (unobservable) utility function were the square root of $X$. Then the risk premium is $\pi=1$, and $a(X) \approx 2(1) / 144=0.01388$. The Pratt-Arrow coefficient of relative risk aversion is $r(X) \approx(37)(2)(1) / 144=0.5139 .10$ Alternatively, using the discrete metrics, $c=11 / 24=0.4583$ and $R=$ 0.1678 . For a second individual of the same age whose utility function is logarithmic and who faces the same risk, the certainty equivalent is 35 years. For this person, $r(X) \approx 1.028$ and $R=0.3429$; (s)he exhibits roughly twice as much aversion to this risk as the first individual. In the following section, we apply both the pointelasticity and arc-elasticity measures to responses from a health preference survey, which incorporates a standard gamble, in order to relate risk aversion to health and demographic variables.

\section{Empirical Application}

Survey Description: The survey contained eighteen questions, most of which have commonly been used in the health preferences literature when measuring risk aversion. Respondents were asked to provide descriptive information including gender, age, income, religion, race, and education, as well as marital and employment status. We also gathered additional information that could affect risk preferences such as the number of dependents, self-reported health status, and smoking habits, in addition to the availability of health insurance and the amount of any life insurance they might have. Because self-reported health status is rather subjective, we also requested more objective health data, including information on any chronic illnesses or disabilities. In addition, height (in inches) and weight (in pounds) were used to construct a body mass index (BMI) for each individual according to the Centers for Disease Control and Prevention (CDC) formula,

$$
B M I=703 x \text { Weight } / \text { Height }{ }^{2} \text {. }
$$

Following CDC guidelines for adults, BMI $\geq 25$ is considered overweight, and BMI $\geq 30$ is considered obese (Centers for Disease Control and Prevention, 2011). To measure the individual's risk preference, we posed a standard gamble question. Because we also wished to test for the presence of endowment effects, two different versions were used. ${ }^{11}$ In version 1 , the question read,

\footnotetext{
${ }^{8}$ If a discrete measure of absolute risk aversion is desired, Eisenhauer and Ventura (2011) propose dividing $R$ by the average of gains and losses; in this case, $[(y-\mu)+(\mu-\beta)] / 2=(y-\beta) / 2$. The resulting measure of absolute risk aversion is not an elasticity, however, and is therefore of less interest than $R$.

${ }^{9}$ Eisenhauer (2008) demonstrates construct validity for $R$.

${ }^{10}$ If the utility function $U(X)=X^{0.5}$ was observable, then $r(X)=0.5$ could be calculated directly from the first and second derivatives. The gap between the exact and approximate values results from measuring aversion to a large risk with a metric designed for small risks.

${ }^{11}$ In the context of consumer goods, the endowment effect indicates that willingness to accept (WTA) exceeds willingness to pay (WTP): an individual who owns a good demands a higher price to sell it than (s)he would pay to buy it if (s)he did not own it. See, for example, Knetch and Wong (2009).
} 
Imagine that you have an illness which does not cause any serious discomfort, but which will ultimately prove to be fatal. Without treatment, there is a $50 \%$ chance of surviving 1 year and a $50 \%$ chance of surviving 25 years. A treatment is available which would allow you to survive this illness for a specific period; the treatment is free, painless, and has no side effects. Please fill in the blank: If it were guaranteed that I would survive at least _ years with the treatment, then I would choose to receive the treatment rather than face the risk of surviving 1 year or 25 years. Thus, in version 1, the respondent was effectively endowed with risk, and was asked at what rate (s)he would trade that risk for the certainty offered by medical treatment. In version 2, the scenario was reversed: the treatment was risky, and the respondent indicated how much certain longevity (s)he would forego to accept the risk. ${ }^{12}$ Appendix 1 contains a complete copy of the final survey instrument (version 1). Subjects were randomly assigned one of the two versions.

We initially distributed the survey as a pilot project to 31 students in an MBA accounting course at a private university in the spring of 2011. The preliminary results indicated that the respondents did not fully understand the standard gamble question. We clarified the wording of this question into its final form (as above) and distributed the revised survey to different classes. The new sample of 92 respondents represented 77 students from four MBA classes at a small private university in the Northeastern U.S. and 15 students from a Master's level course in the Economics of Health and Health Policy at a large public university in the Midwest. Table 1 summarizes the sample characteristics. The respondents' ages ranged from 21 to 59 years with the average respondent being 27 years old. 19 percent were minorities, and females comprised approximately $46 \%$ of the sample. Roughly, two-thirds had never been married, and the average number of dependents was 0.35 . The vast majority reported themselves as being in excellent or good health. More than three-quarters had never smoked, and 12 percent had quit smoking. However, using the BMI, 43\% were found to be overweight, including $9 \%$ who qualified as obese. Eleven percent reported having a chronic illness or disability. Nearly all respondents (98\%) had some form of health insurance, but only about onethird carried life insurance. Three-quarters of the sample were either employed or self-employed. Of these, $4 \%$ reported a high risk of serious injury or illness at work, $16 \%$ reported moderate risk, and $80 \%$ reported low risk. $56 \%$ of the sample reported a household income of less than $\$ 50,000$ per year. In size and composition, our sample was similar to those used in several prior studies. ${ }^{13}$

\section{Results}

Responses to the standard gamble question were highly varied. $6.5 \%$ of the sample failed to answer the question, and $12 \%$ provided economically irrational answers. ${ }^{14}$ After removing those, slightly more than half of the remaining sample (39 out of 75) exhibited risk aversion, as reported in Table 2. The responses ranged

\footnotetext{
${ }^{12}$ Version 2 read: Imagine that you have an illness which does not cause any serious discomfort but which will ultimately prove to be fatal. A treatment is available which provides a 50\% chance of surviving 1 year and a 50\% chance of surviving 25 years. The treatment is free, painless, and has no side effects. Please fill in the blank: If it were guaranteed that I would survive for at least __ years without treatment, then I would choose to forego the treatment rather than face the risk of surviving 1 year or 25 years.
}

${ }^{13}$ The sample sizes in Nakata et al. (2000) and Puhan et al. (2007) were 93 and 96, respectively. Gyrd-Hansen (2002) used a convenience sample of 78 graduate students aged 23 to 58; van der Pol and Ruggeri (2008) surveyed 102 students, 56 percent of whom were male; and Prosser and Wittenberg (2007) used two smaller samples, one of which covered 57 respondents of whom 77 percent were white and 53 percent were female, with an income distribution similar to that of the respondents in our study.

${ }^{14}$ See footnote 3 for the definition. There is a growing literature in behavioral economics, which suggests that irrationality is not uncommon, especially when respondents confront important and complex decisions; see, for example, San Miguel et al. (2005) and Ariely (2008). In a health context, San Miguel et al. (2005) found that between 5.5 percent and 20.6 percent of respondents failed rationality tests. 
from infinitely risk averse $(C=B)$ to infinitely risk loving $(C=G) \cdot{ }^{15}$ Because the gamble fixes $\mu=13$ and $\sigma^{2}=144$, we have $a(X)=2 \pi / 144$. Then for an individual whose current age is denoted by $X_{0}$, the PrattArrow coefficient of relative risk aversion is calculated as $r(X)=2\left(X_{0}+13\right)(\pi) / 144$. The coefficient of relative risk aversion ranged from -11.5 to 11.0 , with a mean of 0.0586 and a median of 0.833 . The arc elasticity measure of risk aversion, $R$, is calculated according to (9). The distribution of $R$, which ranged from negative infinity to positive infinity, was bimodal at -0.34 and +0.53 , with a median of 0.17 ; among its finite values the mean was 0.0585 . There was no statistically significant difference in the means of the two preference metrics.

Table 1: Demographic Characteristics

\begin{tabular}{ll}
\hline Characteristic & Percentage \\
\hline Male & $54 \%$ \\
White & $81 \%$ \\
Catholic & $53 \%$ \\
Protestant & $19 \%$ \\
Never Married & $64 \%$ \\
Married & $20 \%$ \\
Unwed Partner & $13 \%$ \\
Divorced/Separated & $3 \%$ \\
Employed & $71 \%$ \\
Self-employed & $4 \%$ \\
Unemployed & $10 \%$ \\
Not in Labor Force & $15 \%$ \\
Income $\$ 25,000$ & $36 \%$ \\
\$25,000-\$50,000 & $20 \%$ \\
\$50,000-\$75,000 & $16 \%$ \\
\$75,000-\$100,000 & $9 \%$ \\
Income > $\$ 100,000$ & $19 \%$ \\
Graduate Degree & $36 \%$ \\
Excellent Health & $32 \%$ \\
Good Health & $65 \%$ \\
Fair Health & $3 \%$ \\
Never Smoked & $78 \%$ \\
Quit Smoking & $12 \%$ \\
Smokes Occasionally & $7 \%$ \\
Smokes Regularly & $3 \%$ \\
Chronic Illness/Disability & $11 \%$ \\
Overweight & $43 \%$ \\
Obese & $9 \%$ \\
Group Health Insurance & $64 \%$ \\
Military Health Insurance & $2 \%$ \\
Individual Health Insurance & $11 \%$ \\
Public Health Insurance & $1 \%$ \\
Other Health Insurance & $20 \%$ \\
Life Insurance & $33 \%$ \\
\hline
\end{tabular}

\footnotetext{
${ }^{15}$ Note that the Pratt-Arrow coefficients fail to recognize these responses as infinite risk aversion and infinite love of risk; rather, for $C=B, a(X)=0.1667$ and for $C=G, a(X)=-0.1667$. Eisenhauer (2010a) observes the same phenomenon.
} 
Table 2: Risk Preferences

\begin{tabular}{ll}
\hline Risk Preference & Percentage \\
\hline Infinitely risk averse & $8 \%$ \\
Finitely risk averse & $44 \%$ \\
Risk neutral & $1 \%$ \\
Finitely risk loving & $31 \%$ \\
Infinitely risk loving & $16 \%$ \\
\hline
\end{tabular}

Our investigation of the endowment effect took the form of a simple chi-square test of independence. Subjects who responded to version 1 of the standard gamble were more likely to be risk averse than those who responded to version 2 , and the difference was significant at the (two-tailed) .084 level. Thus, individuals endowed with risk appeared to be somewhat more averse to it than those endowed with certainty that were given the option to choose risk. To put this result another way, there appeared to be greater aversion to a naturally occurring health risk than to a comparable risk arising from medical care. To examine the effects of individual characteristics on risk preferences, we conducted multiple linear regressions of demographic variables on both $r(X)$ and $R$. Using backward elimination, we began with a full slate of independent variables and removed those with the most insignificant $t$-statistics. Several iterations are reported in Tables 3 and 4. The respondent's current age and the number of dependents were both continuous variables; the other independent variables were indicators. The dummy for relationship status took the value 1 if the individual was in an unwed domestic partnership, and zero otherwise; the performance of alternative indicators (for example, 1 if married and 0 otherwise) was not substantially different.

In general, the regressions run on $r(X)$ showed less explanatory power (adjusted R-square) than those run on $R$ : less than 15 percent for the former compared with 19 to 26 percent for the latter. In none of the regressions was race, religion, or age statistically significant. ${ }^{16}$ In both sets of regressions, a high risk of occupational injury or illness was correlated with lower aversion to risk. This most likely reflects a self-selection pattern: those who are inherently more tolerant of health risk (i.e., least risk averse) are most likely to accept physically risky jobs. Although relationship status was not significant, the presence of dependents had a significant positive effect on health-related risk aversion: those who bear responsibility for other human beings' welfare were less willing than those without dependents to accept physical risks to themselves. Somewhat surprisingly, the presence of life insurance was not a significant factor. That result may reflect a data quality issue: it appeared that many respondents were unsure whether they had life insurance coverage, and if so, how much. It is also likely that most of those who had coverage had received it as an employee benefit rather than having deliberately purchased a policy, in which case their coverage may not reflect risk preferences. Health insurance was similarly insignificant. This is not surprising, since the choice to accept, a free treatment would not be expected to depend on health insurance. ${ }^{17}$

Three variables, which have been widely tested in other risk preference studies, are gender, income, and education. Among the most widely replicated results in the financial risk literature is the finding that women are more risk averse than men (Levin, et al., 1988; Powell and Ansic, 1997; Jianakoplos and Bernasek, 1998; Hammitt et al., 2009; Neelakantan, 2010; von Gaudecker et al., 2011). We obtained this same result with the arc elasticity measure, but not with the point elasticity measure. Indeed, for $r(X)$, the coefficient on Male had the theoretically wrong sign and lacked statistical significance. Likewise, previous work shows that risk aversion declines with education (Eisenhauer, 2008; Eisenhauer and Ventura, 2011; von Gaudecker et al., 2011). While all of our subjects were enrolled in graduate school, some had already completed a prior graduate degree. Compared with prior research, the education coefficient had the wrong sign and lacked significance in the point elasticity regressions. By contrast, the results for the arc elasticity measure $R$

\footnotetext{
${ }^{16}$ Prior research indicates higher risk aversion among the elderly, but the age range in our sample did not permit us to compare elderly against non-elderly individuals.

${ }^{17}$ Because the overwhelming majority of respondents had some form of health insurance, we combined 'other' with 'none' to generate the indicator.
} 
conformed to our expectations: the presence of a pre-existing graduate degree reduced risk aversion. ${ }^{18}$ In addition, household income was insignificant in the point elasticity regressions, whereas the regressions with the arc elasticity measure indicated that lower-income individuals were more risk averse than higher-income individuals; the latter finding corresponds with most prior research on financial risk (Eisenhauer, 2008; Hammitt et al., 2009; Eisenhauer and Ventura, 2011). Controlling for income, however, the unemployed showed a lower degree of risk aversion than their employed counterparts did, though the effect was only marginally significant on the arc elasticity measure $R$.

Table 3: Regression Results for $\mathrm{r}(\mathrm{X})^{*}$

\begin{tabular}{|c|c|c|c|c|c|c|}
\hline Variable & $\begin{array}{l}\text { Coeff } \\
\text { [prob] }\end{array}$ & $\begin{array}{l}\text { Coeff } \\
\text { [prob] }\end{array}$ & $\begin{array}{l}\text { Coeff } \\
\text { [prob] }\end{array}$ & $\begin{array}{l}\text { Coeff } \\
\text { [prob] }\end{array}$ & $\begin{array}{l}\text { Coeff } \\
\text { [prob] }\end{array}$ & $\begin{array}{l}\text { Coeff } \\
\text { [prob] }\end{array}$ \\
\hline \multirow[t]{2}{*}{ Constant } & -0.108 & -0.055 & -0.056 & -0.722 & -0.501 & -0.545 \\
\hline & {$[.975]$} & {$[.987]$} & {$[.986]$} & {$[.701]$} & {$[.777]$} & {$[.755]$} \\
\hline \multirow[t]{2}{*}{ Age } & -0.038 & -0.039 & -0.035 & & & \\
\hline & {$[.719]$} & {$[.701]$} & {$[.715]$} & & & \\
\hline \multirow[t]{2}{*}{ Male } & 0.762 & 0.797 & 0.817 & 0.672 & 0.718 & 0.738 \\
\hline & {$[.582]$} & {$[.533]$} & {$[.512]$} & {$[.568]$} & {$[.520]$} & {$[.505]$} \\
\hline \multirow[t]{2}{*}{ White } & 0.851 & 0.858 & 0.725 & 0.723 & 0.680 & 0.672 \\
\hline & {$[.626]$} & {$[.619]$} & {$[.662]$} & {$[.635]$} & {$[.646]$} & {$[.647]$} \\
\hline \multirow[t]{2}{*}{ Protestant } & -04.24 & -0.419 & & & & \\
\hline & {$[.788]$} & {$[.788]$} & & & & \\
\hline \multirow[t]{2}{*}{ Relationship Status } & 0.129 & & & & & \\
\hline & {$[.944]$} & & & & & \\
\hline \multirow[t]{2}{*}{ Dependents } & 1.541 & 1.549 & 1.577 & 1.447 & 1.463 & 1.399 \\
\hline & {$[.098]$} & {$[.091]$} & {$[.077]$} & {$[.044]$} & {$[.038]$} & {$[.040]$} \\
\hline \multirow[t]{2}{*}{ Grad Degree } & 0.537 & 0.538 & 0.544 & & & \\
\hline & {$[.751]$} & {$[.748]$} & {$[.727]$} & & & \\
\hline \multirow[t]{2}{*}{ Unemployed } & -4.698 & -4.693 & -4.863 & -4.987 & -4.982 & -5.002 \\
\hline & {$[.031]$} & {$[.029]$} & {$[.018]$} & {$[.013]$} & {$[.012]$} & {$[.011]$} \\
\hline \multirow[t]{2}{*}{ High Risk Job } & -6.328 & -6.356 & -6.188 & -5.779 & -5.990 & -5.706 \\
\hline & {$[.063]$} & {$[.058]$} & {$[.055]$} & {$[.055]$} & {$[.046]$} & {$[.048]$} \\
\hline \multirow[t]{2}{*}{ Income $<\$ 50,000$} & -1.078 & -1.098 & -1.152 & -1.128 & -1.054 & -1.100 \\
\hline & {$[.440]$} & {$[.416]$} & {$[.379]$} & {$[.373]$} & {$[.395]$} & {$[.369]$} \\
\hline \multirow[t]{2}{*}{ Life Insurance } & 0.414 & 0.406 & & & & \\
\hline & {$[.799]$} & {$[.800]$} & & & & \\
\hline No/Other & -1.816 & -1.822 & -1.797 & -1.721 & -1.603 & -1.525 \\
\hline Insurance & {$[.332]$} & {$[.325]$} & {$[.322]$} & {$[.331]$} & {$[.335]$} & {$[.352]$} \\
\hline \multirow[t]{2}{*}{ Excellent Health } & 0.863 & 0.853 & 0.857 & .868 & 0.765 & 0.788 \\
\hline & {$[.520]$} & {$[.518]$} & {$[.507]$} & {$[.494]$} & {$[.535]$} & {$[.519]$} \\
\hline \multirow[t]{2}{*}{ Chronic Illness/Disability } & -1.011 & -1.031 & -0.890 & -0.873 & -0.795 & \\
\hline & {$[.643]$} & {$[.630]$} & {$[.665]$} & {$[.664]$} & {$[.686]$} & \\
\hline \multirow[t]{2}{*}{ Smoker } & 4.481 & 4.488 & 4.478 & 4.597 & 4.671 & 4.589 \\
\hline & {$[.056]$} & {$[.053]$} & {$[.045]$} & {$[.031]$} & {$[.025]$} & {$[.026]$} \\
\hline \multirow[t]{2}{*}{ Overweight } & 0.486 & 0.473 & 0.551 & 0.503 & & \\
\hline & {$[.710]$} & {$[.712]$} & {$[.650]$} & {$[.672]$} & & \\
\hline R-square & .271 & .271 & .269 & .266 & .263 & .260 \\
\hline Adj. R-square & .028 & .048 & .082 & .114 & .129 & .142 \\
\hline SE & 4.6210 & 4.5739 & 4.4901 & 4.4127 & 4.3441 & 4.3115 \\
\hline
\end{tabular}

*Two-tailed prob-values in brackets

\footnotetext{
${ }^{18} \mathrm{~A}$ chi-square test showed no significant difference in risk preferences between the graduate students in Economics and those in Business.
} 
Table 4: Regression Results for $\mathrm{R}^{*}$

\begin{tabular}{|c|c|c|c|c|c|c|}
\hline Variable & $\begin{array}{l}\text { Coeff } \\
\text { [prob] }\end{array}$ & $\begin{array}{l}\text { Coeff } \\
\text { [prob] }\end{array}$ & $\begin{array}{l}\text { Coeff } \\
\text { [prob] }\end{array}$ & $\begin{array}{l}\text { Coeff } \\
\text { [prob] }\end{array}$ & $\begin{array}{l}\text { Coeff } \\
\text { [prob] }\end{array}$ & $\begin{array}{l}\text { Coeff } \\
\text { [prob] }\end{array}$ \\
\hline \multirow{2}{*}{ Constant } & -3.418 & -3.332 & -3.187 & -2.705 & -2.716 & -1.240 \\
\hline & {$[.260]$} & {$[.260]$} & {$[.268]$} & {$[.310]$} & {$[.304]$} & {$[.560]$} \\
\hline \multirow[t]{2}{*}{ Age } & 0.094 & 0.092 & 0.089 & 0.084 & 0.089 & 0.076 \\
\hline & {$[.323]$} & {$[.324]$} & {$[.330]$} & {$[.341]$} & {$[.309]$} & {$[.372]$} \\
\hline \multirow[t]{2}{*}{ Male } & -2.077 & -2.004 & -1.972 & -1.830 & -1.863 & -1.792 \\
\hline & {$[.082]$} & {$[.074]$} & {$[.074]$} & {$[.084]$} & {$[.076]$} & {$[.084]$} \\
\hline \multirow[t]{2}{*}{ White } & 1.148 & 1.163 & 1.158 & 1.113 & 1.249 & \\
\hline & [.399] & {$[.385]$} & {$[.381]$} & {$[.388]$} & {$[.321]$} & \\
\hline \multirow[t]{2}{*}{ Protestant } & 0.765 & 0.821 & 0.795 & 0.698 & & \\
\hline & {$[.558]$} & {$[.514]$} & {$[.521]$} & {$[.562]$} & & \\
\hline \multirow[t]{2}{*}{ Relationship Status } & 0.325 & & & & & \\
\hline & {$[.839]$} & & & & & \\
\hline \multirow[t]{2}{*}{ Dependents } & 1.275 & 1.291 & 1.296 & 1.224 & 1.231 & 1.311 \\
\hline & {$[.084]$} & {$[.074]$} & {$[.069]$} & {$[.071]$} & {$[.067]$} & {$[.048]$} \\
\hline \multirow[t]{2}{*}{ Grad Degree } & -2.328 & -2.350 & -2.306 & -2.247 & -2.396 & -2.766 \\
\hline & {$[.118]$} & {$[.109]$} & {$[.109]$} & {$[.105]$} & {$[.077]$} & {$[.038]$} \\
\hline \multirow{2}{*}{ Unemployed } & -3.459 & -3.446 & -3.506 & -3.601 & -3.707 & -2.879 \\
\hline & {$[.134]$} & {$[.130]$} & {$[.117]$} & {$[.100]$} & {$[.086]$} & {$[.123]$} \\
\hline \multirow[t]{2}{*}{ High Risk Job } & -6.971 & -7.007 & -7.065 & -6.888 & -6.900 & -7.143 \\
\hline & {$[.024]$} & {$[.021]$} & {$[.018]$} & {$[.018]$} & {$[.016]$} & {$[.012]$} \\
\hline \multirow{2}{*}{ Income $<\$ 50,000$} & 2.453 & 2.412 & 2.403 & 2.309 & 2.303 & 2.432 \\
\hline & {$[.058]$} & {$[.056]$} & {$[.053]$} & {$[.049]$} & {$[.048]$} & {$[.036]$} \\
\hline \multirow[t]{2}{*}{ Life Insurance } & 1.527 & 1.532 & 1.479 & 1.425 & 1.349 & 1.366 \\
\hline & {$[.272]$} & {$[.263]$} & {$[.269]$} & {$[.276]$} & {$[.296]$} & {$[.286]$} \\
\hline No/Other & 0.433 & 0.438 & & & & \\
\hline Insurance & {$[.777]$} & {$[.771]$} & & & & \\
\hline \multirow[t]{2}{*}{ Excellent Health } & 0.608 & 0.592 & 0.565 & & & \\
\hline & {$[.592]$} & {$[.595]$} & {$[.606]$} & & & \\
\hline \multirow[t]{2}{*}{ Chronic Illness/Disability } & -1.983 & -2.044 & -2.074 & -2.081 & -2.092 & -2.185 \\
\hline & {$[.232]$} & {$[.205]$} & {$[.191]$} & {$[.181]$} & {$[.174]$} & {$[.152]$} \\
\hline \multirow[t]{2}{*}{ Smoker } & 7.162 & 7.248 & 7.155 & 6.897 & 6.784 & 6.795 \\
\hline & {$[.002]$} & {$[.001]$} & {$[.001]$} & {$[.001]$} & {$[.001]$} & {$[.001]$} \\
\hline \multirow[t]{2}{*}{ Overweight } & -1.479 & -1.523 & -1.500 & -1.601 & -1.554 & -1.781 \\
\hline & {$[.194]$} & {$[.167]$} & {$[.166]$} & {$[.128]$} & {$[.135]$} & {$[.082]$} \\
\hline R-square & .452 & .451 & .450 & .445 & .440 & .416 \\
\hline Adj. R-square & .186 & .209 & .229 & .250 & .263 & .256 \\
\hline SE & 3.3124 & 3.2654 & 3.2225 & 3.1592 & 3.1318 & 3.1273 \\
\hline
\end{tabular}

*Two-tailed prob-values in brackets

Self-reported health status had no significant effects on either the point-elasticity or arc-elasticity measure of risk aversion. Neither weight status nor the chronic illness/disability indicator showed a strong level of significance, and in the point elasticity regressions, these two indicators generated opposite signs. In the arc elasticity regressions, by contrast, the two indicators yielded the same negative sign and the weight indicator was marginally significant; the latter finding is consistent with the results of Anderson and Mellor (2008). We thus have weak evidence that those in poor health are less averse to health risks than those in better health. This finding contrasts with prior research showing that those in poor health are more averse to financial risks (Eisenhauer and Ventura, 2011). At the same time, however, smokers exhibited greater aversion to the proposed health risk than non-smokers in both sets of regressions. Prior research tends to suggest that smokers are less averse than non-smokers to financial risks (Barsky, et al., 1997; Eisenhauer, 2000; Anderson and Mellor, 2008), and indeed, Hersch (1996) assumes that smoking is a priori evidence of risk tolerance. 


\section{Conclusion}

Our study suggests the following tentative conclusions. First, tolerance of health risk may be influenced by an endowment effect. That is, aversion to risk appeared to be greater when longevity was uncertain without medical care than when medical treatment caused the uncertainty. This could suggest an inherent faith or confidence in medical care, such that patients prefer the risks associated with treatment to the risk from not having treatment. This seems quite reasonable, given the asymmetry of medical information: patients recognize that their knowledge of health care is inferior to that of their physicians. Second, those who face a high risk of occupational illness or physical injury appear to be more tolerant than others of health risks. Third, several of the same factors that affect financial risk preferences may also affect health-related risk preferences; these include gender, education, income, and the presence of dependents. However, the arcelasticity measure of risk aversion captures more of the significant differences and has a stronger correlation to demographic and socio-economic variables than does the more traditional point-elasticity measure of relative risk aversion. This adds to the growing body of evidence, which suggests that the conventional measures of risk aversion are ill suited to large-scale risks such as those involving health.

Finally, we also find some evidence that health-related risk preferences differ from financial risk attitudes in at least two respects. Whereas prior research suggests that smokers are more tolerant of financial risks than non-smokers, the current study finds smokers to be significantly less willing than non-smokers to take additional health risks. On the other hand, whereas prior research shows those in poor health to be more averse to financial risk, we find them less averse than healthier individuals to health-related risks. Several important caveats regarding this data set are pertinent to these findings. In particular, because the sample is relatively small and largely homogeneous, it is dangerous to extrapolate the results to broader populations. In addition, responses to hypothetical survey questions must inevitably be interpreted with caution, since there is no safeguard for respondent veracity. Thus, as in any research, the results presented here are not conclusive. They do, however, provide a basis for replication and a justification for additional study on the measurement of risk aversion with regard to health.

Acknowledgement: The authors wish to thank Dr. John McAlearney for assistance with data collection, and an anonymous referee for helpful comments. Any errors are our own.

\section{References}

Anderson, L. A. \& Mellor, J. M. (2008). Predicting health behaviors with an experimental measure of risk preference. Journal of Health Economics, 27(5), 1260-1274.

Ariely, D. (2008). Predictably Irrational: The Hidden Forces that Shape our Decisions. NY: Harper Collins.

Arrow, K. J. (1965). Aspects of the Theory of Risk Bearing. Helsinki: Yrjo Jahnsson.

Barsky, R. B., Juster, F. T., Kimball, M. S. \& Shapiro, M. D. (1997). Preference parameters and behavioral heterogeneity: An experimental approach in the Health and Retirement Study. Quarterly Journal of Economics, 112(2), 537-579.

Ben-Zion, U. \& Gafni, A. (1983). Evaluation of public investment in health care: Is the risk irrelevant? Journal of Health Economics, 2(2), 161-165.

Centers for Disease Control and Prevention (2011). About BMI for Adults. http://www.cdc.gov/healthyweight/assessing/bmi/adult_bmi/index.html , February 15.

Eeckhoudt, L., Gollier, C. \& Schlesinger, H. (2005). Economic and Financial Decisions under Risk. Princeton: Princeton University Press.

Eisenhauer, J. G. (2000). Estimating prudence. Eastern Economic Journal, 26(4), 379-392.

Eisenhauer, J. G. (2006). Risk aversion and prudence in the large. Research in Economics, 60(4), 179-187.

Eisenhauer, J. G. (2008). Attitudes toward large-scale risks: A discrete estimation using Dutch data. European Journal of Economics, Finance and Administrative Sciences, 10, 138-150.

Eisenhauer, J. G. (2010a). Rank ordering of risk preferences with conventional and discrete measures. Quarterly Review of Economics and Finance, 50(3), 291-297.

Eisenhauer, J. G. (2010b). A simple metric for gauging risk aversion. Asia-Pacific Journal of Risk and Insurance, $4(2)$, article 6: 1-10. 
Eisenhauer, J. G. \& Ventura, L. (2003). Survey measures of risk aversion and prudence. Applied Economics, 35(13), 1477-1484.

Eisenhauer, J. G. \& Ventura, L. (2011). Interval risk aversion. Applied Economics, 43(9), 1139-1150.

Gyrd-Hansen, D. (2002). Comparing the results of applying different methods of eliciting time preference for health. European Journal of Health Economics, 3(1), 10-16.

Hammitt, J. K., Haninger, K. \& Triech, N. (2009). Effects of health and longevity on financial risk tolerance. Geneva Risk and Insurance Review, 34(2), 117-139.

Heinzel, C. (2009). Long run choice behavior under uncertainty in finance, the economics of risk and time, and applied economic studies: A review of literature and recent advances. University of New South Wales, July.

Hersch, J. (1996). Smoking, seat belts, and other risky consumer decisions: Differences by gender and race. Managerial and Decision Economics, 17(5), 471-481.

Jianakoplos, N. A. \& Bernasek, A. (1998). Are women more risk averse? Economic Inquiry, 36(4), 620-630.

Johannson, P. O. (1995). Evaluating Health Risks: An Economic Approach. Cambridge: Cambridge University Press.

Knetch, J. L. \& Wong, W. K. (2009). The endowment effect and the reference state: Evidence and manipulations. Journal of Economic Behavior and Organization, 71(2), 407-413.

Law, A. V., Pathak, D. S. \& McCord, M. R. (1998). Health status utility assessment by standard gamble: A comparison of the probability equivalence and the lottery equivalence approaches. Pharmaceutical Research, 15(1), 105-109.

Levin, I. P., Snyder, M. A. \& Chapman, D. P. (1988). The interaction of experiential and situational factors and gender in a simulated risky decision-making task. Journal of Psychology, 122(2), 173-181.

Meyer, D. J. \& Meyer, J. (2005). Measuring Risk Aversion. Hanover, MA: Now Publishers.

Nakata, Y., Okuno-Fujiwara, M., Goto, T. \& Morita, S. (2000). Risk attitudes of anesthesiologists and surgeons in clinical decision making with expected years of life. Journal of Clinical Anesthesia, 12(2), 146-150.

Neelakantan, U. (2010). Estimation and impact of gender differences in risk tolerance. Economic Inquiry, 48(1), 228-233.

Oliver, A. \& Cookson, R. (2010). Analyzing risk attitudes to time. Health Economics, 19(6), 644-655.

Powell, M. \& Ansic, D. (1997). Gender differences in risk behavior in financial decision-making: An experimental analysis. Journal of Economic Psychology, 18(6), 605-628.

Pratt, J. W. (1964). Risk aversion in the small and in the large. Econometrica, 32(1-2), 122-136.

Prosser, L. A. \& Wittenberg, E. (2007). Do risk attitudes differ across domains and respondent types? Medical Decision Making, 27(3), 281-287.

Puhan, M. A., Schunemann, H. J., Wong, E., Griffith, L. \& Guyatt, G. H. (2007). The standard gamble showed better construct validity than the time trade-off. Journal of Clinical Epidemiology, 60(10), 1029-1033.

San-Miguel, F., Ryan, M. \& Amaya-Amaya, M. (2005). Irrational stated preferences: A quantitative and qualitative investigation. Health Economics, 14(3), 307-322.

Torrence, G. W., Furlong, W. \& Feeny, D. (2002). Health utility estimation. Expert Reviews of Pharmacoeconomics \& Outcomes Research, 2(2), 99-108.

Van-der-Pol, M. \& Ruggeri, M. (2008). Is risk attitude outcome specific within the health domain? Journal of Health Economics, 27(3), 706-717.

Verhoef, L. C. G., De-Haan, A. F. J. \& Van-Daal, W. A. J. (1994). Risk attitude in gambles with years of life. Medical Decision Making, 14(2), 194-200.

Von-Gaudecker, H. M., van-Soest, A. \& Wengstrom, E. (2011). Heterogeneity in risky choice behavior in a broad population. American Economic Review, 101(2), 664-694. 